\title{
Being (in the Midst of) Two: \\ Interstice and deconstitution in cinema and architecture
}

\author{
Michael Tawa
}

Woodland Crematorium,

Stockholm (Asplund and

Lewerentz 1935-1940)/Maldives

[All photographs are by the author]

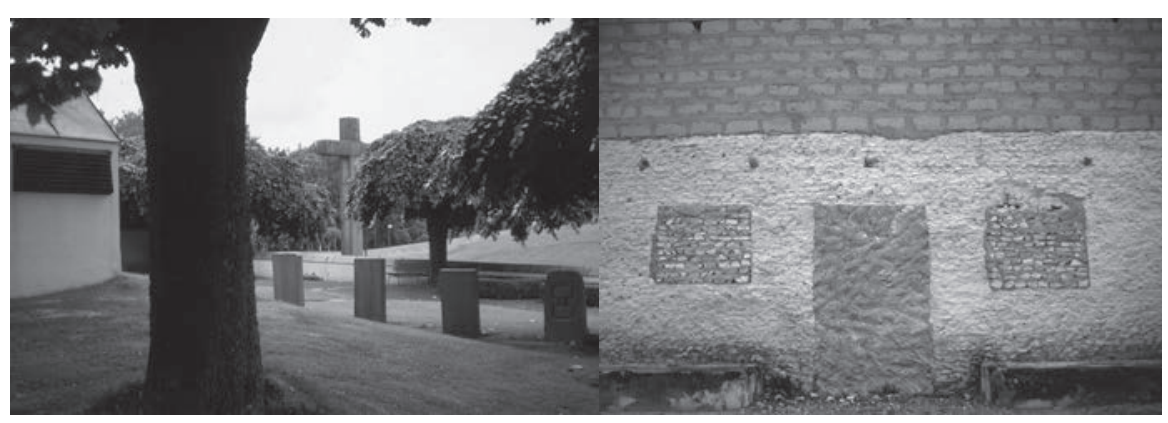

Not knowing the way out or the way in, wonder dwells in a between, between the most usual, beings, and their unusualness, their 'is.' It is wonder that first liberates this between as the between and separates it out. Wonder-understood transitively-brings forth the showing of what is most usual in its unusualness. Not knowing the way out or the way in, between the usual and the unusual, is not helplessness, for wonder as such does not desire help but instead precisely opens up this between, which is impervious to any entrance or escape, and must constantly occupy it. (Heidegger 1994: 145)

We are human beings because we are outbound (en partance), disposed towards a departure about which we can and must know that no definitive arrival is possible or promised. It is in this impulse (élan), in the obligation of departure, since we cannot do otherwise, and in this risktaking (prise du risque), in the wager of departure, that we can live a life worth living. (Nancy 2011: 29-30)

\section{Interval}

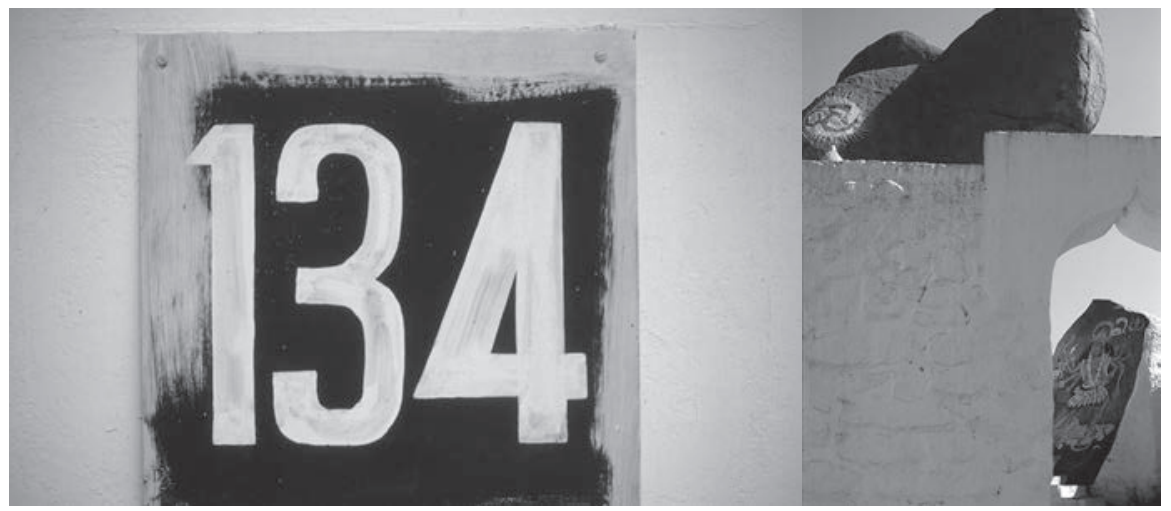


The story I wish to put to you today is simple. I would like to begin with the beginning of architecture, which is also the beginning of the possibility of life-that is, the interval which makes space and time possible, which gives us room to be and to breathe. I want to extend this sense of the interval into a common trope, commonly misconstrued-that is, duality, the duality between the interval and the walls it spaces-out: in other words, the duality between the limit and the limited, or in architectural terms, between inside and outside, private and public. I would like to suggest that this duality does not logically, factually or existentially exist.

Duality arises from the incapacity to hold two conditions simultaneously-light and dark, for example, grief and humour, or self and other. As such it arises when time is conceived diachronically or chronologically as a succession of instants. Classical narrative, whether cinematic or spatial/architectural, is founded on the disassociation, in sequential time and linear space, of what is in reality coincident and synchronic. If duality is recast as a condition of being-two, that is of beingsimultaneously-dual-private and public, inside and outside, on screen and off screen, now and then, here and there, virtual and actual-then what first appears ambiguous in its oppositional indeterminacy turns out, for a moment, to eclipse the antinomical in favour of something more complex, indistinguishably interfolded or inwardly-concatenated.

Beings and worlds are folded, woven or felted out of beings within beings, worlds within worlds, scales within scales and rhythms within rhythms. As such they are states of what Gilbert Simondon called "surfused" or "supersaturated metastability" that take their fabric (psychosomatic, filmic, tectonic) to a threshold of crisis at which two things happen: the fabric reaches a limit of compaction or intensity and it begins to dilate and unravel (Simondon 2007: 16). This unraveling produces a new state or emergent condition that could not have been planned or predicted. The function of a work (a text, a film, a building) is to frame and provide situations in which such emergence is enabled. Such framing and providing is a matter of care or solicitude. It is properly speaking a technics, a manner of doing something and the know-how that attends to it, a mnemotechnics that is also mnemoethics-a watching and waiting, being-with and being-for that solicits the coming-into-presence of something: a mood, an atmosphere, an emotion, an insight, an exchange, an idea, a project, a melody, a word, a phrase, an expression, a recollection, a person, a place. This is what any work (text, film, building) is made-for.

\section{Entr'acte: in medias res (in the midst of things)}

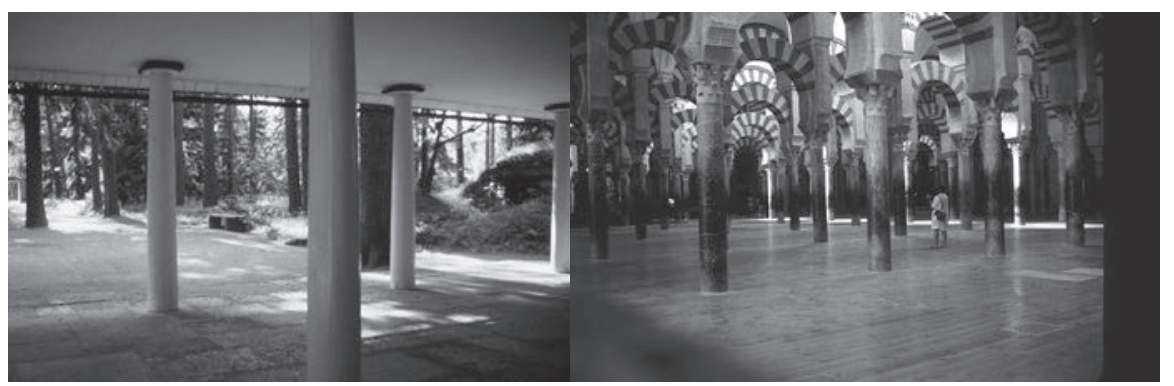

Woodland Chapel (Asplund 1918-1920)/ Mosque, Cordoba (7-10thC)]

Jean-Luc Godard's thinking of the entr'acte, of cinema as the interstitial transition between shots and scenes, situates the cinematographic work as a process of joining images and their traces-that is, as a properly technological (techne) concern (Tawa 2010: 136, 165-7, 290-3). Greek techne is equivalent to Latin ars, and means to 
connect, to articulate, to weave, to create a nexus-all of which are tactics constitutive of a technics; a taxis that refers as much to tectonic assemblage as it does to the tact of an ethical and the tactility of an oneiric practice. This in-between, interstitial site of praxis is neither void nor neutral. It is a terrain with a topography that can be charted and investigated. The milieu is not an intermediate terrain vague, an empty pause or chasm-it is itself a world, or a whorl of worlds within worlds. The mythological tradition is full of such intermittent middle-places-Midgard (middle-yard/enclosure), Mittelerde (middle-earth) and Greek oikomene (ecumene, household economy) all refer to the intermediate world of human existence, poised between giants and dwarfs, gods and demons, heaven and hell. The interstice, or the gape at the core of every junction, is what makes possible the strength of a connection, the capacity of a space and the rotation of a wheel. Yet the gap is also a site of deconstruction. Deconstitution or deconstruction is fundamentally a process that takes place at the joints-where analysis loosens (Latin: ana-lusis = to loosen apart) and liquidates the knots that constitute an assemblage. The shuttle has the same function in weaving. It moves in the gaps and interstices of warp and weft, infiltrates the hollows and fuses or names-together-across (diakrinomen) warp and weft into an interconnected network to weave (sumploxe) the fabric. The nexus is therefore a site of both strength and weakness-a pivot of assemblage and disassemblage, construction and destruction, creation and catastrophe.

\section{Whorls of worlds}

The Mirror (Tarkovski, 1979) [All drawings from the film are by the author]

\footnotetext{
1 The autobiographical and political registers of the film have been much commented on, as has its concern for aligning Tarkovsky's personal reminiscences and
} poetic reflections with specific instances of Russian history. See Dunne (2008), Le Fanu (1987), Jónsson and Óttarsson (2006). Here I limit myself to the primary sources of the film and Tarkovsky's own text to frame a reading of the film's existential and compositional dimensions and show how its tectonic and material qualities are used to foreground the role of the interstice and discrepancy in the operation of memory and recollection (see Tarkovsky 2006). My focus precludes literature that deals with other aspects of Tarkovsky's work-for example his concern with space and temporality, evidenced notably in The Mirror, Stalker (1979) and The Sacrifice (1986) by tracking shots through enfilades of architectural interiors which double with the interiority of his subjects; by a concern for the relationship between the spaces and objects that furnish human dwelling and "absorb" its traces; or by the deterioration of world and subject leaving behind apocalyptic conditions of subsistence. See for example the extended treatment of Tarkovsky's use of tracking shots in Martin (2011), and "spatio-temporal lapse" and discontinuity across Tarkovsky's work as described by Skakov (2011).

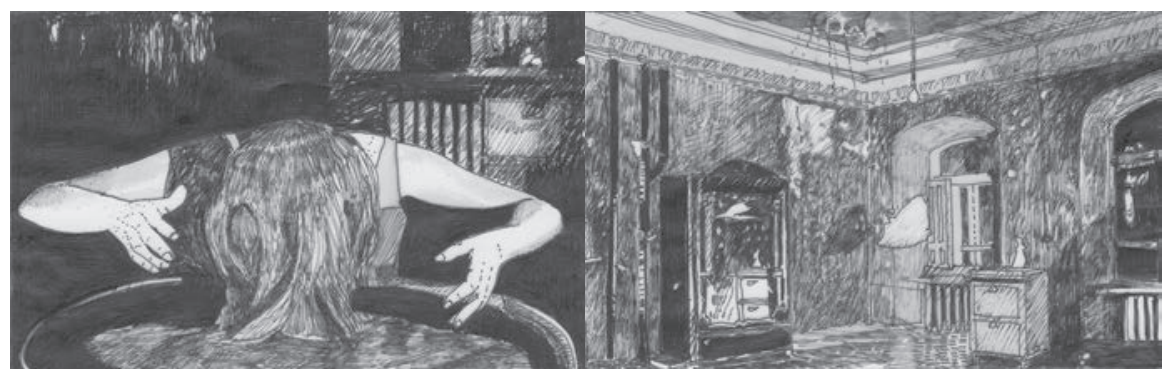

I would like to interpret a sequence from Andrei Tarkovsky's The Mirror (1979) in line with the main narrative I am relaying, proceeding from the deconstitution of the subject, of space and time through intensification and crisis to emergence and solicitude. ${ }^{1}$ By a systematic concatenation of interstitial discontinuities, Tarkovsky builds up and conjugates a series of images that function like resonant metaphors. The film achieves such an intensity of overlay that the coordinates and logics of space and time become undecidable and fold into complex worlds within worlds. Simultaneously, the compaction of images and metaphors, paralleling an overlap of reminiscences for the narrator, densify the semantic materiality of the image to such a degree that its consistency begins to develops fault lines, to falter and threaten collapses. In this extraordinary sequence, the narrator remembers himself as a child before his mother's dressing table mirror. As he looks into it, the scene shifts to the past and to his young mother washing her hair, framed within a dark space glistening with reflections from oil-black walls, wet skin, clothing and mirrors dissimulated into the background. As she stands, dripping, the entire room begins to weep water from all surfaces and collapse. The scene then shifts to a dark room, presumably the same room at a later time, in which the author's now elderly mother approaches the glass. The mirror doubles a window set alongside it, 
suggesting a black night outside. It is unframed and so does not read as an opening in a wall like the window beside it, but as pure surface and pure aperture.

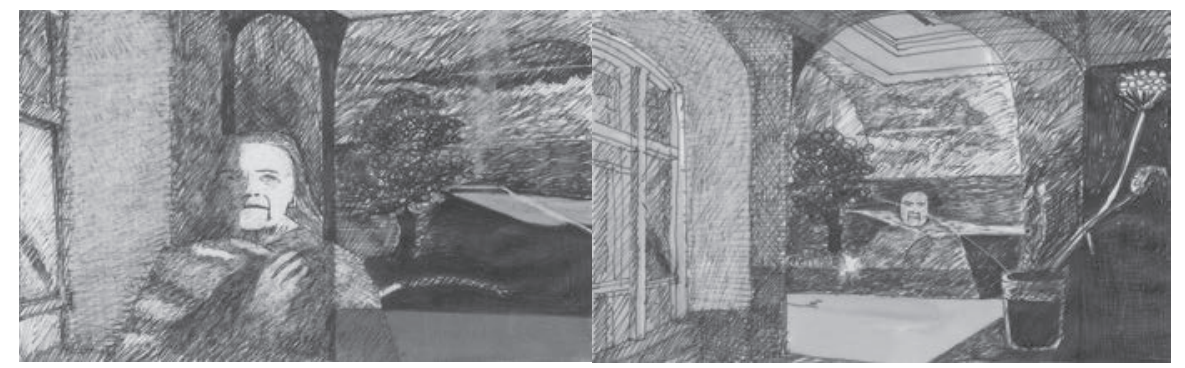

The mirror's position in the room is ambiguous and it appears suspended in space rather than fixed to the wall. Its transparent immateriality reflects multiple overlaid images-a painted twilight landscape of clouds, earth or sea, tree and open fire; reflections of a ceiling cornice and floral wallpaper patterns in the room behind; images of the remaining cornice and wallpaper behind its surface; a floating plane like a table that reinforces the threshold; reflections of the arched window and the mother nearing the mirror's surface, as if from its other side. She raises her hand and places it on the glass. This gesture not only validates but also produces the duality of the two sides and the filmic boundary that separates them. She looks into the mirror as if questioning the materiality of its surface, as if it were on the verge of yielding and giving access to the multiple spatialities and temporalities of memory. The surface of a mirror operates in several ways, but always as a cipher of cinema itself. It is a filmic screen onto which images are projected-but from both directions-and exchanged into both of the spaces that front onto its surface. It is a frame which delimits and veils compossible worlds; a translucent doorway connecting places and times; an apparatus of memory, recollection and projection and a surface of monstration.

The collapse of the room marks a crisis in the concrete reality and existential milieu of the scene. The actual time of the sequence is left ambiguous since multiple temporalities are simultaneously fielded. There is clearly a looking back to the author's childhood in the early scenes. The old mother might herself be looking back, looking forward, returning from the dead or returning to meet her younger self. The question is less a matter of conveying chronological accuracy than of showing the circulation of real and imagined, actual and virtual, remembered and projected places, times and events within a single setting made possible by and within this interstitial rupture. The implausibility of the event amplifies this condition of crisis, enabling the images to convey more realistically what an experience of this rupture might feel like. It is not only the room that collapses but also the spatial, temporal and subjective coordinates of concrete existence. The moment triggers a disorientation in the subject and an avalanche of images which had welled up, to only now break through the resistance of forgetfulness-just as water violates the architectural skin and takes with it all guarantee of stability, shelter and safety. The sequence works metaphorically to convey, through a monstrous architectural catastrophe, the exposure of consciousness to a surfeit of the repressed memory and potentiality of the subject. 


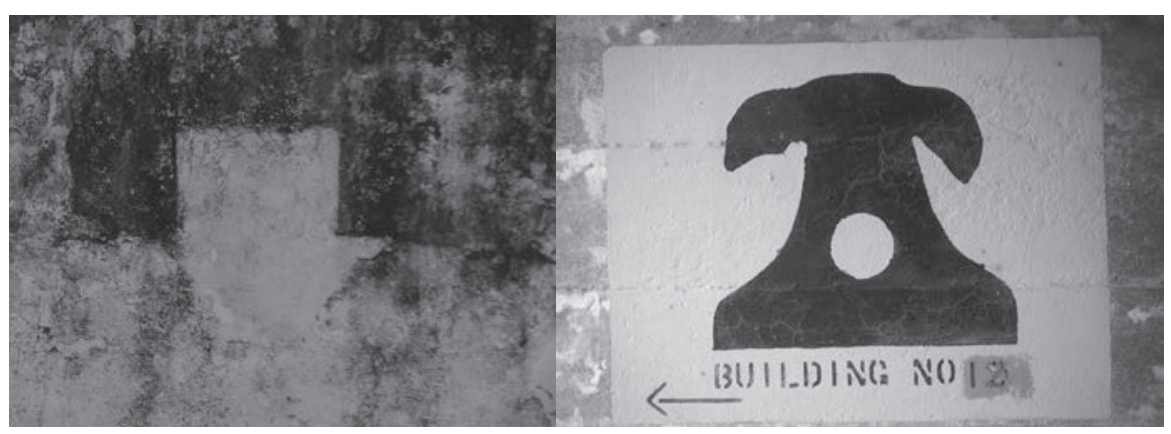

These instances parallel a constitutive condition of remembering and a defining characteristic of the apparatus of memory: that remembering and memorialisation-or monumentalisation, since the idea is cognate-is not a matter of attaining or evidencing accurate or even adequate reminiscence. Rather, it is fundamentally about making a place for the difficulty and impossibility of remembering; a space in which we can be with memory as it fades and withdraws or evades our grasp, and yet remains just there, on the tip of the tongue; an experience of that moment betwixt remembrance and forgetfulness when a memory withdraws into oblivion at the same time as it presents itself with the highest certainty of delineation. Memory is poised on forgetting and remembrance is in fact the iterative, rhythmic play between appearance and disappearance, recollection and oblivion, presence and absence. This is why the proper field and operation of memory is not conditioned by the antinomy of light and dark, but by the gloaming-an ambiguous and precarious, interstitial condition or shade of darkness wherein delineations fluctuate and become indeterminate. The experience might be like awaking from a dream that, at the same time as it is present to us as sharp recollection, fades and withdraws into uncertainty. Each time we try to remember, the narrative is dismantled into incoherence. Or the experience might parallel one's presence and attentiveness to the systematic withdrawal of another in death; of one who is palpably present and with us while simultaneously fading and absenting themselves. Such moments require delicacy and care. They call for a kind of disengaged solicitude that watches, wakes and waits; that cultivates a countenance of being-with and being-for whatever eventuates. This is the ethical power of the interstice that architecture remains to confront.

To accommodate or furnish a space for this calls for a technics of resistance where the materiality of the field we happen to be working (in)-light, time and narrative for cinema, space, time and materiality for architecture; or the gravity of thought and the weight of words for language-plays an impressive, constitutive and formal role. I wish to make the point that the workings of memory are not virtual or insubstantial. They are deeply and intricately material, even as the traces they leave seem evanescent. As Lyotard notes, after Bergson, "mind is matter that remembers" its origins, interactions, transactions and immanence (1992: 40)-a reading supported by the common linguistic basis of an extensive lexicon: human, man, mind, mnemonic, memory, memorial, monument, moon, month, measure, metre, matter and mother, through the etymons ${ }^{*} \mathrm{MEN}=$ to think and ${ }^{*} \mathrm{MA} / \mathrm{ME}=$ to measure, weigh up, consider, reflect. 


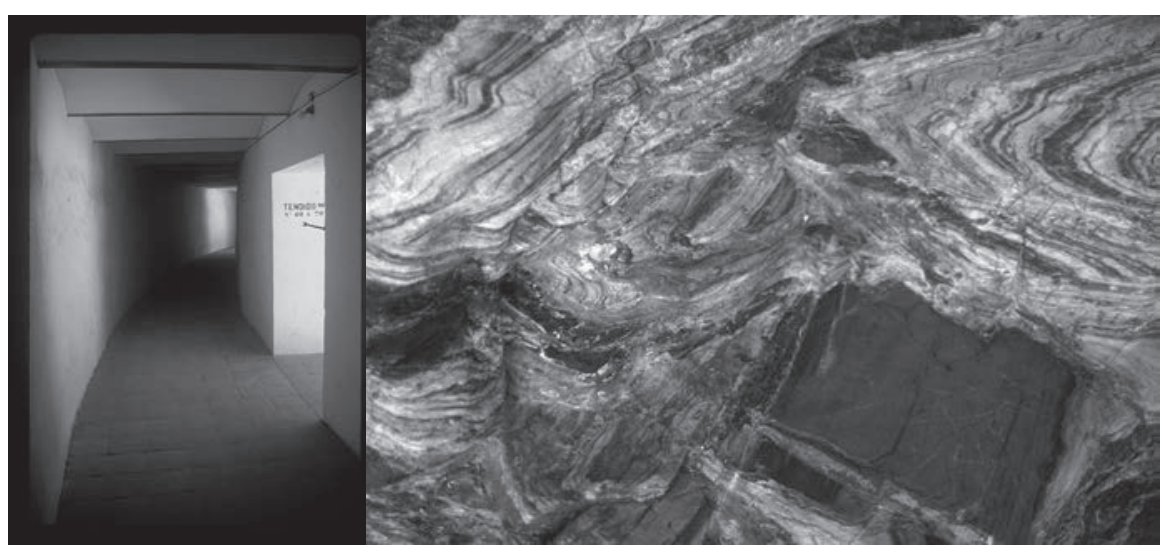

That is to say human being is fundamentally mnemonic and recollective (Greek: anamnesis = without-forgetting). Photography and film might be the preeminent arts of recollection, but cinema differs in that it shows the traces of memory passing, it shows the process of their withdrawal and erasure into oblivion. With cinema we witness time and all that it conditions pass us by and depart from uspersonalities, families, communities, peoples, narratives, histories, landscapes, creatures, emotions, melodies, airs, tones, rhythms, beats, ideas, theories, phrases, words, voices, whispers. These all have material being and they affect and impress us materially. Consequently we are ourselves mnemotechnical. To use Bernard Stiegler's phrasing, we are "retentional apparatuses" that register and record the passage of what has passed us by (2008: 122-3). We are archives and museums, laboratories and studios of recreation and renewal. Since architecture is fundamentally a technical undertaking, its key function must be to operate as a mnemotechnical apparatus or infrastructure which tracks, frames and unclenches traces and recollections-of self, of place, of moments, of encounters. How might architecture do this?

Following his assertion that the proper concern of cinema is not to "realistically" convey the factuality of events but to capture their "reality", Tarkovsky makes a telling observation about the way imagination, dreams and recollections can be conveyed in cinema:

How is it possible to reproduce what a person sees within himself, all his dreams, both sleeping and waking? ... It is possible, provided that dreams on the screen are made up of exactly these same observed, natural forms of life. Sometimes directors shoot at high speed, or through a misty veil ... But that mysterious blurring is not the way to achieve a true filmic impression of dreams or memories. The cinema is not, and must not be, concerned with borrowing effects from the theatre. What then is needed? First of all we need to know what sort of dream our hero had. We need to know the actual material facts of the dream; to see all the elements of reality which were refracted in that layer of the consciousness which kept vigil thorough the night ... And we need to convey all of that on screen precisely, not misting it over and not using elaborate devices. Again, if I were asked, what about the vagueness, the opacity, the improbability of a dream?-I would say that in cinema 'opacity' and 'ineffability' do not mean an indistinct picture, but the particular impression created by the logic of the dream: unusual and unexpected 
combinations, and conflicts between, entirely real elements. These must be shown with the utmost precision. By its very nature, cinema must expose reality, not cloud it. (2006: 72)

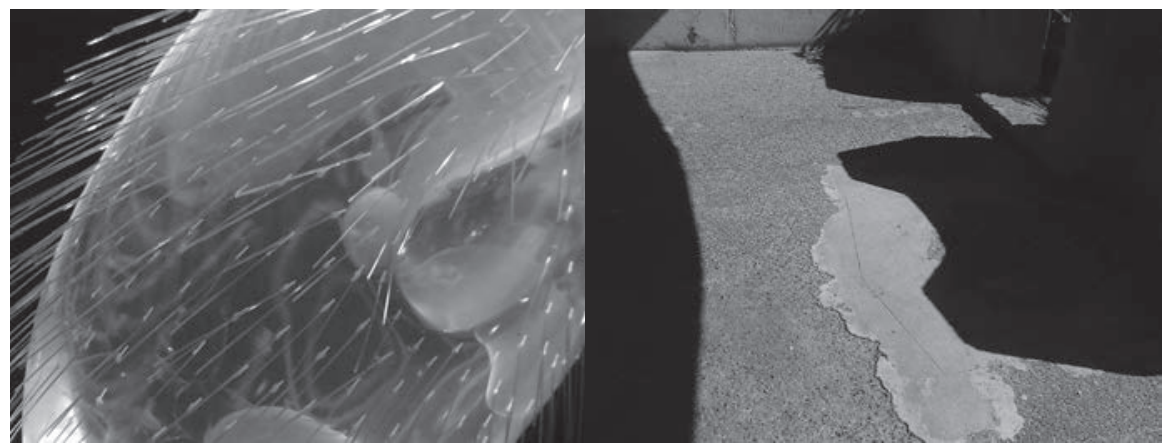

For Tarkovsky this is not to be sought in special effects or literal translation, but in the focused and intensified working of the materials and technologies of film itself, paying close attention to the inherent logic of the moment being conveyed. Cinematographers achieve this quality in very different ways-in Tarkovsky's The Mirror by intensifying the material conditions of the image and the time it takes to pass; in Nicolas Roeg's Bad Timing (1980) by switching between multiple timeframes with great velocity; in David Lynch's Lost Highway (1996) by disestablishing psychic and concrete spatialities and temporalities to produce radically altered, parallel states of being; in Carlos Reygadas' Silent Light (2007) by turning the cinematic frame to pure attention and watching-out-for whatever comes; and in Jean-Luc Godard's Histoire(s) du Cinéma (1988-1998) by montage which juxtaposes, multiplies and densifies narrative texture.

In every case, the strategies and tactics of manipulating temporality are deployed entirely within the fundamental limits of cinematic production-the 24-per-second frame-rate limit of image projection-rather than by adopting practices that lie outside the tectonics of cinema. This suggests that a work will persuasively engage with the real only by intensively working its fundamental limits, rather than by eliminating or escaping them. What implications might there be for architecture of this cinematic eclipse of time within time itself? How might the agency of cinema allow architecture to conceptualise a parallel eclipsing of space within space itself, and how might this deterritorialise architecture, opening it up to the strange and the unfamiliar? 


\section{Deconstitution}

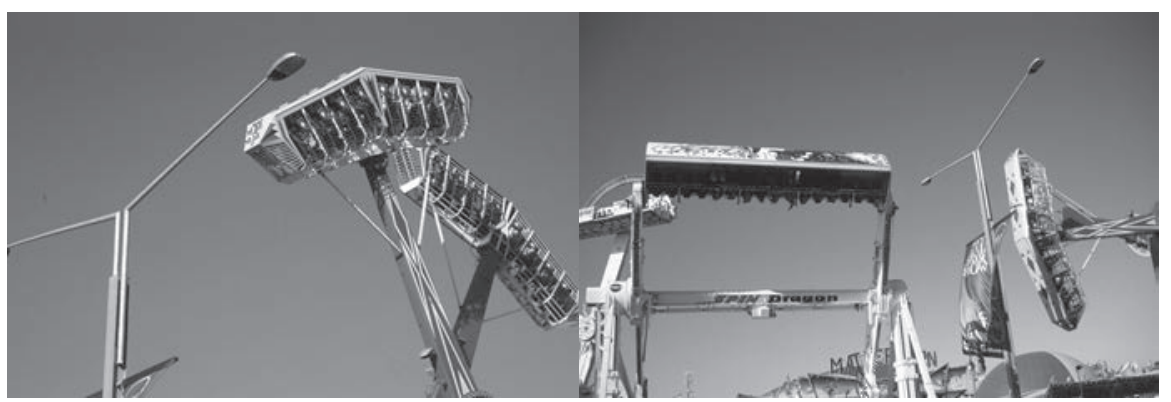

Much current architectural theory and practice declares an urgency for engaging with contemporary realities in which certainty and stasis no longer hold, where universals have no purchase, where fluctuation and interminable variation condition experience, and where the disconnected and fragmented are commonplace. In response, architects look to formal systems and modes of working which privilege the dynamic and the ambiguous. Attracted to so-called non-Euclidean geometries and rhizomatic networks, embedding design in the diagramming of fluctuations in global markets, political deterritorialisations or other kinds of statistical analyses and parametric modeling, architects look for relevance in the conditions, needs and demands of a contemporary world in a state of crisis. As a result, architecture becomes a mimetic and formal representation of the dynamic, fluctuating, unsettled, unpredictable and catastrophic lineaments of that crisis. But in doing so, it merely trades one form of mimesis-the imitation or reification of transcendent permanent realities-for another: the imitation of immanent impermanent fluxion. It continues to adhere precisely to the literalness that Tarkovsky warned against. It is not a question of finding "elaborate devices" to represent certain conditions or to displace certain accepted modes of working. Rather, it is a question of remaining and working with(in) the foundational and familiar existential characteristics, elements and processes of reality in order to convey and amplify its unsettling and uncanny dimensions. The implication for architecture is that the most unsettling, the most unfamiliar and extraordinary experiences happen to take place precisely in the midst of the most ordinary and mundane of circumstances.

A musical example of how the uncanny might be produced by working within and through the tectonic conditions of music and into the texture of time itself might be Arvo Pärt's Festina Lente (1988-90). In this composition the same melody is played simultaneously by three groups of instruments at three different time scales-slow, natural and fast. The instruments begin together but the disjunction in tempo causes the three streams to immediately diverge. During the piece, these three will develop radically different dynamic and harmonic relationships as they separate, cross over or align with each other. This simple structural and procedural system results in a disassociated assemblage that sometimes magnifies and sometimes fractures the melodic and rhythmic material. The resulting affects range from resonance and concord to complete discord and chaotic deconstruction of the melody, from dynamic alignment, up-gathering and amplification to extreme opposition and cancellation of energy. Festina Lente is an investigation of music as the logical playing out of interstitial difference within a tectonics of time. The contradiction in the music's title-festina lente means "to hurry slowly"also defines its ambit. By overlaying one melodic pattern with its accelerated and decelerated variations, Pärt constructs an enigmatic image of time in the process 
of unraveling and decompressing-where the present is put into tension and stress by the antagonistic of a propellant future and a restraining past. The piece thus moves from stable regular organisation to irregular coagulations of multiple layers; then inexorably towards deconstitution as the texture of the piece disentangles into broad horizontal sheets of sound decreasing in proximity, separated by intervals growing in distance, eventually fading to an indefinitely deferred and infinitely finishing end.

A similar enigmatic quality, spatial this time, is evident in the architecture of Sigurd Lewerentz. Colin St John Wilson reads the enigma in terms of Lewerentz' own guiding motto: "Mellanspel"-meaning a playing (spel) between (mellan). He contends that Lewerentz sets up then plays out various antinomical, oppositional themes to create discrepancy, ambiguity, indeterminacy and obliquity within an apparently simple spatial setup. From that results a sense of inexplicability or "mystery" that St John Wilson implies might be proper to the experience of a sacred building (St John Wilson 2001: 21). The discrepancies that Lewerentz installs in the geometry and materiality of the Church of St Peter, Klippan (1963-66), confirm this reading. The plan is square rather than basilican, therefore centralised rather than linear. In an ideal square no single direction predominates. But Lewerentz carefully and forcefully differentiates between several axes that constitutively bisect the space. The single column appears central but is in fact asymmetrical in both north-south and east-west directions within a space that is exactly square (north is uppermost in the plans). The column's axis of symmetry is offset from the geometric centre and axis of symmetry of the room. The altar is not centralised but located just to one side of this axis. These discrepant axial symmetries produce an extremely charged space.

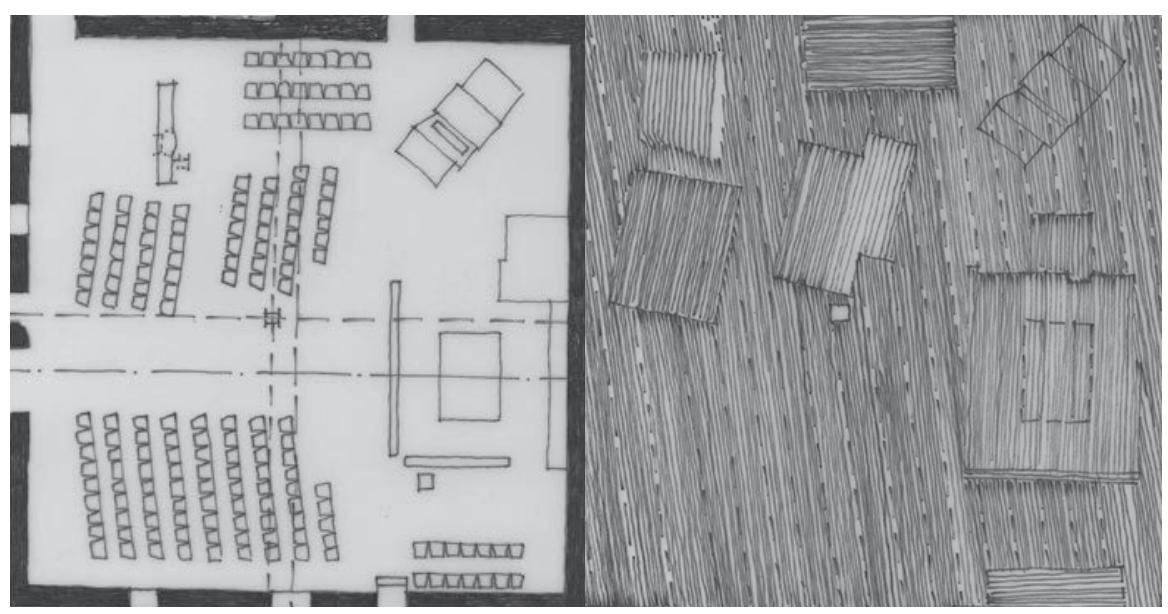

Lewerentz works further geometrical alignments, directions and dynamics into the space to contest the apparent simplicity of the square, distort its rational order and install a strange dislocation with tectonic, experiential, theological and liturgical registers. The vaulted ceiling billows in uneven waves due to the alternating pattern of ribs, which expand and contract in plan as well as slope slightly towards the centre of the space from each side. The undulating brick ceiling is read against a pair of deep steel beams that span the full width of the space. These are supported on a primary beam, almost imperceptibly asymmetrical to the single column that supports it. The asymmetry of the column is reinforced by the offset 
assembly of beams-the two major cross beams also having the effect of countering the orientation of the vaults. This steel assembly effectively subdivides the square chapel into four smaller regions. The altar is marginally offset to the south of the central axis of the room and placed in the quadrant opposite the entry door. The baptismal font is in the quadrant closest to the entry. In both cases this is in accordance with normal liturgical practice. The lectern and organ occupy the third quadrant and the major portion of the congregation occupies the fourth. None of the windows or doors is symmetrical to or aligned with the geometric axes of the whole space, or with the quadrants in which they are located. The combined effect of this highly complex but barely perceptible setup, made of very slight nuanced geometrical shifts and overlays, is considerable.

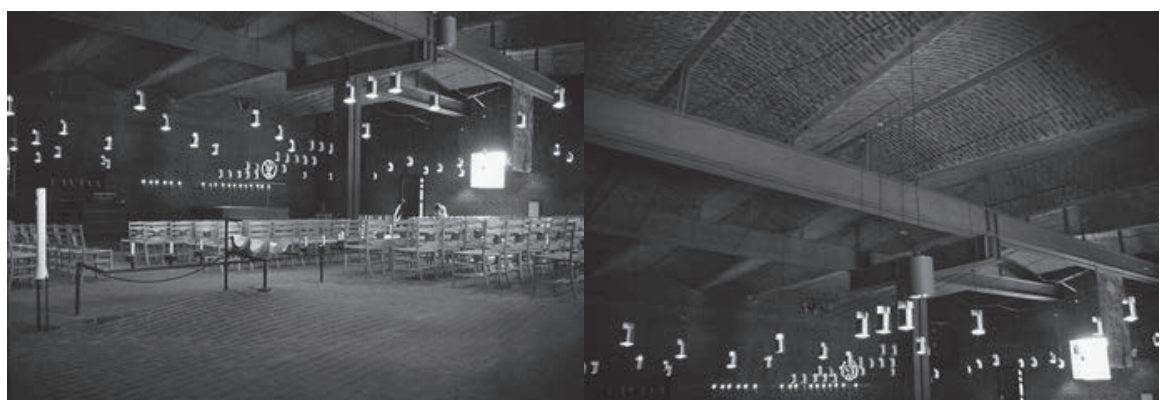

In terms of directionality and dynamics, the ceiling vaults run west-east towards the altar to emphasise a processional direction. At the same time, they rise from each side to a north-south pitching ridge above the column assembly. The combined effect is to stretch the west-east dimension and to gather, centralise and raise the space upward. This tension between two tendencies holds the space in suspense, in an indiscernible state somewhere between stability and dissolution. In the brick floor the bed joints run north-south, but at an angle to the square plan. Within this linear pattern Lewerentz inserts several areas of paving at other angles-like rugs or patches set within a larger web. Despite reading more like a woven multidirectional surface than a linear array, the heterogeneous patterning of the floor counters the orthogonal alignment of the overall space and the altar, as well as the walls. The directionality of the paving resists and decelerates that of the vaults. These contrasting shifts in pattern and geometry create disjunctions and incommensurabilities in the spatial order of the room.

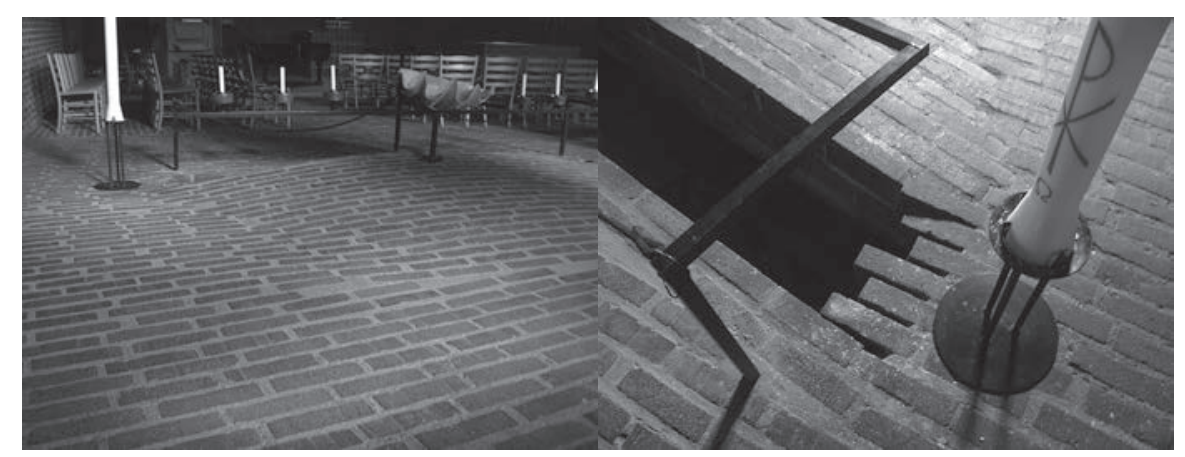

St Peter. Main chapel brick floor and baptistery
St Peter. Main chapel, brick floor, steel framing and brick vaults.
This intricate juxtaposition of geometries, spatial directions, tensions and proportions tends to overburden, materialise and condense the space: but also to mobilise 
its materiality, causing it to fluctuate, alternate and oscillate-but quietly, slowly and in a minor key. Tectonic implications exceed any semantic, metaphorical or symbolic readings that could be ventured for the building. The central armature that supports the roof may evoke the cross on Calvary but it also zones the space to frame a differentiated collectivity. It produces a weighty, grave ambience that matches the simultaneous grief and joy of reflection, prayer and celebration that define the Protestant mass. It turns an abstract spatial structure into a world or place, calibrated to specific modes of being, being-with and -without others and being-with-otherness. The multiple interstices between geometric systems within what appears to be a simple, resolved space produce a disturbance and uncanny presence that parallels the theological condition of a God who is neither immanent nor transcendent, but has effectively withdrawn and abandoned human beings who must henceforth both mourn His departure and await His return. Lewerentz does not achieve this architectural metaphor of a complex metaphysical circumstance through formal complexity, large-scale compositional tropes or unusual geometries. The scale of tectonic endeavour is extremely modest yet every move carries considerable weight and enduring affect. He does not abandon architecture's foundational tectonic dimensions or remit but critically crafts the tectonic by subjecting it to significant strain and working at it until it yields.

In each example from cinema, music and architecture, the interstice or gap plays a key role in conveying meaning and narrative. The interstice is produced in the midst of each work, in their very structure and fabric, by arranging component parts so that discrepancies arise to contest the overall order. In Pärt's Festina Lente the discrepancy is durational and due to three coexisting time signatures or temporalities. These three play out simultaneously to produce disjunctions that sometimes build and amplify and sometimes deconstruct the rhythmic and melodic texture of the music. Pärt uses the tectonic potential of music to convey the ambiguous, wavering and enigmatic condition of "hurrying slowly"-as the title of the composition suggests. In The Mirror, the discrepancy is found between narrative and image, due to a disjunction between the narrative and temporal conditions of linking scenes. The resulting sequence produces disjunctions in time, in the content of the narrative and subject matter of the images and in the existential state of the subjects who appear to exist across multiple timeframes. The coexistence of these disjunctions with the smooth and often slow filmic sequence produces a discordant texture in the film to convey a limit point with crisis or emergency in the protagonist's experience of recollection. Finally, with Lewerentz' Church of St Peter, numerous discrepancies are used to disturb the stability of an apparently centralised, masonry building to create an entirely interstitial fabric. The geometric order is built of unaligned centres, axes and symmetries, while the building's material density and weight is systematically given over to undulation and levitation-for example, in the sloped, heaving floor and the alternating rhythms of the vaulted ceiling that seems to billow above the space. These tectonics parallel a theological motif central to the Christian experience-the discrepancy between human and divine that worship is made to address. At the same time, the interstitial discrepancies lead to ambiguous, undecidable spatial and material systems whose incommensurabilities develop a wavering, shimmering quality that eclipses the space's geometric and material limits-producing tectonic parallels to the mysterious and transformative dimensions of worship.

As a result of the deconstitutive interstice, musical time is no longer solely linear and diachronic but also circular and synchronic. It no longer solely advances but also folds back and returns into itself. Cinematic time is no longer solely limited by the disassociation of past, present and future but can also enable these to coexist 
and affect each other. Architectural order is no longer solely limited to singular harmonised spatial systems but can also incorporate multiple, unaligned systems to produce indeterminate and ambiguous orders. Likewise, masonry is no longer solely compounded by its material weight but can also convey immateriality and levity. Such enigmatic qualities are realisable because of the interstice, because of the disassociative capacity of the interstice to enable multiple systems to coexist, to come into productive contact and consequently to fundamentally disturb and challenge the prevailing order. Such disturbances are not destructive but productive. They enable complex, nuanced systems of order to coexist within a single assemblage, but without recourse to expanded fields or practices that might seek to eclipse a given art form or discipline. The production of simultaneously consilient and discrepant conditions, mobilised and structured by the interstice and achieved entirely by working the foundational material, tectonic opportunities and tactics inherent to cinema, music and architecture, creates assemblages in which nothing is as it seems and everything remains open to investigation, interpretation and uncanny, emergent potential.

\section{References}

Dunne, N. (2008). Tarkovsky. London: Black Dog Publishing.

Le Fanu, M. (1987). The cinema of Andrei Tarkovsky. London: British Film Institute.

Godard, J.-L. (2002). The future(s) of film, three interviews, 2000-01. Berlin: Gachnang \& Springer.

Heidegger, M. (1994). Basic questions of philosophy: Selected "problems" of "logic" (R. Rojcewicz \& A. Schuwer, Trans.). Bloomington \& Indianapolis: Indiana University Press.

Jónsson, G., \& Óttarsson, T. (2006). Through the mirror: Reflections on the films of Andrei Tarkovsky. Newcastle upon Tyne: Cambridge Scholars Press.

Lyotard, J.-F. (1992). The inhuman: Reflections on time (G. Bennington \& R. Bowlby, Trans.). Stanford, CA: Stanford University Press.

Martin, S. (2011). Andrei Tarkovsky. Harpenden: Kamera Books.

Nancy, J-L. (2011). Partir - Le départ. Montrouge: Bayard.

St John Wilson, C. (2001). Sigurd Lewerentz: The sacred buildings and the sacred sites. In N. Flora, P. Giardiello \& G. Postiglione (Eds.), Sigurd Lewerentz 1885-1975 (17-23). Milan: Electa.

Simondon, G. (2007) L'Individuation psychique et collective. Paris: Aubier/Flammarion.

Skakov, N. (2011). The cinema of Tarkovsky: Labyrinths of space and time. London: I. B. Tauris.

Stiegler, B. (2008). Économie de l'hypermatériel et psychopouvoir. Paris : Mille et une Nuits.

Stiegler, B. (2008). Prendre soin : Tome 1, De la jeunesse et des générations. Paris: Flammarion.

Tarkovsky, A. (2006). Sculpting in time: Reflections on the cinema (K. Hunter-Blair, Trans.). Austin: University of Texas Press.

Tawa, M. (2010). Agencies of the frame: Tectonic parallels in cinema and architecture. Newcastle upon Tyne, UK: Cambridge Scholars Publishing.

Tawa, M. (2011). Theorising the project: A thematic approach to architectural design. Newcastle upon Tyne, UK: Cambridge Scholars Publishing. 